\title{
The impact of Involvement in CRM Initiative on Inter-functional Integration and Organizational Performance: Evidence from Pakistani Enterprises
}

\author{
${ }^{*}$ Muhammad Ashraf ${ }^{1}$, Asad Afzal Hamyon², Mohammad Asif Khan³, Noor Ismawati Jaafar' ${ }^{1}$, Ainin Sulaiman ${ }^{1}$ \\ ${ }^{1}$ University of Malaya, Malaysia \\ ${ }^{2}$ COMSATS Institute of Information Technology, Pakistan \\ ${ }^{3}$ Institute of Business \& Technology, Karachi, Pakistan \\ *muhammadashraf@siswa.um.edu.my
}

\begin{abstract}
Customer Relationship Management (CRM) is IT based system that manage customer long term relationship, and also inter-function relationship within the organization with the ultimate purpose of creating customer value by sharing concise, sufficient, accurate, reliable, and timely valuable information has greatly enhanced inter-functional integration (IFI) and organizational performance (OP). The purpose of this study is to examine the relationship among three constructs: 1) Involvement (IN) of marketing and IT departments in CRM initiative, 2) IFI, and 3) OP, and presents conceptual model based on this relationship in which involvement in CRM initiative can affect OP either directly or indirectly through IFI. Data collected based on online survey from 30 large companies in Pakistan are analyzed in accordance with research objectives by using correlation, descriptive statistics, simple linear regression and other statistical tools of SPSS. Research findings suggest that involvement in planning, implementation, and usage of CRM system has positive but no significant immediate effect on OP and instead that it improves $\mathrm{OP}$ via indirect significant and potential positive effect on IFI highlight the importance for management to endorse IFI and consider involvement of stakeholders in CRM initiative as enabler.
\end{abstract}

Keywords: CRM, Involvement, Inter-functional Integration, Organizational Performance, planning, implementation, marketing, Information Technology

\section{Introduction}

With the increasing competition among companies, technological development, customization of products and services, and reducing product lifecycles, companies are striving for maintaining competitive advantages. Addition to this, customer's demand is becoming more selective and sophisticated (Galbreath, 1998; Abbott et al., 2001). Along with these factors, accelerating pace of new technologies and emergence of new channels like the internet, have changed how companies interact with their customers (Parvatiyar and Sheth, 2001) and have increased and improved the chances and possibilities of managing better relations with their customers. In this regard, the customer relationship management (CRM) approach has received increased attention in marketing thought during the last three decades (Wahlberg et al., 2009). At the core of this approach is the use of IT based systems (CRM systems) to manage customer relationships, and also relationships within an organization with the ultimate purpose of creating customer value (Payne, 2002). Although there are several definitions of $\mathrm{CRM}$ in the previous literature, CRM is primarily concerned with managing the relationships of the companies with their customers in order to deliver the customer services and value by emphasizes on efficient and effective flows of information within and outside the organization; beginning from the delivery of the raw materials to the consumptions of final products by the consumers. The management of these processes require strong interaction and collaboration among the different functions; i.e. information technology (IT), production, marketing, sales, after sales services, in order to achieve ultimate organizational objectives of increased customer value and reducing cost. Consequently, a large number of organizations have implemented or in the process of implementing CRM system in order to streamline CRM activities.

After a long standing academic research and intense discussion on payoff from investment of time and money in CRM system implementation, there is lake of clear consensus in the literature. Few researchers found that overall CRM technology is positively associated with organizational performance (Isaksson, 2005; Payne, 2006; Kim and Lee, 2010); others have reported that investment in CRM system provides competitive advantages (Grandhi and Chugh, 2012). Despite such outstanding success of investment in 
CRM system; several companies also reported failure to achieve desired results from CRM initiative. According to the research conducted by Butler Group; approximately 70\% of all CRM initiatives unable to delivering expected results that can be called "IT paradox" (Kohli and Devaraj, 2003).

Previous research has identified different reasons for such failures of CRM implementation, but one reason for failure that has received wide acceptance in literature is the lack of Interfunctional integration and communication (Ryals and Knox, 2001; Meyer, 2005; Isaksson, 2005; Payne, 2006; Nguyen et al., 2007). A strong Interfunctional relationship between the IT department and the marketing department is central to the eventual acceptance of such a system. When the members of the marketing and IT departments interact or involve in CRM initiative, they can reach mutual agreements on both how the system can be used and how it can be developed to match the marketing departments' needs. This is of importance to the eventual success of a CRM implementation initiative, since it affects the perceived ease of use, the perceived usefulness and, subsequently, the acceptance of a CRM system (Davis, 1989). Fundamental to any Interfunctional relationship is that it is based upon a communication between the departments involved. This communication can be conducted into three different ways: i) interpersonal interaction ii) written interaction, and iii) collaboration. Thus, the involvement of marketing department in CRM system implementation initiative boosts the Interfunctional integration as well organizational performance.

There could be another open question regarding the way or manner in which CRM system implementation impacts organizational performance (OP). Most of the studies conducted in identifying and examining the benefits of CRM implementation (Sigala, 2004; Krasnikov et al., 2009). These researches provide insight into the overall advantages of CRM implementation, while OP is affected by several factors other than the focal CRM implementation (Dehning and Richardson, 2002; Isaksson, 2005). Thus, it can be concluded on the basis literature review that Inter-functional integration (IFI) can greatly improve the OP (Gupta et al., 1985; John and Hall, 1991; Griffin et al., 1996; Souder, 1977; Kahn et al., 1996; Ryals and Knox, 2001; Meyer, 2005; Isaksson, 2005; Payne, 2006; Kim and Lee, 2010). The advantage can be derived from the fact that CRM implementation makes possible information sharing and other forms of collaboration within or outside the organization. For instance, sales force automation and jointly developed market demand forecasting. But, if involvement in CRM initiative does not have direct impact on OP, it may have indirect impact via its effect on the processes developed for IFI. This possibility has drawn little attention and less discussion in the long standing academic research literature. The research question that is intended to answer in this study is: Does and how do involvement (IN) in CRM initiative affects IFI and OP?

The purpose of this study is to enhance our understanding of how involvement in CRM initiative affects IFI and OP. Three propositions are proposed based on the literature review to empirically examine the immediate or direct effect of involvement in CRM initiative on OP and indirect effect on OP mediated by IFI. The remaining part of this study is arranged as follows; first, a conceptual model of the relationship among Involvement in CRM initiative, IFI, and OP is presented. Second, a brief and concise literature review, and a set of three research propositions relevant to the developed conceptual model are proposed. Third, research methodology and empirical findings are explained and presented. Fourth, discussion of the research results and managerial implications are provided. Finally, conclusion of this study followed by its limitations and future research avenues is presented.

\section{Literature Review}

Development of Conceptual Model: A conceptual model of the relationship among involvement (IN) in CRM initiative, IFI, and OP is proposed (See figure 1). According to the conceptual model, Involvement in CRM initiative can enhance OP not only directly, but also indirectly through its effect on IFI. The involvement of marketing department can be done in three different phases of CRM initiative; i) planning, ii) implementation, and iii) usage of CRM system. When the members of the marketing and IT departments interact, they can reach mutual agreements on both how it can be developed and implement to match the marketing departments' needs and how the system can be used. In this study, organizational performance (OP) is used rather than financial performance only, because CRM initiative has direct significant impact on OP like building an attractive virtual community, effective communication to customer, better marketing information management, expansion and effectiveness of marketing campaign, increase in return of marketing investment, improvement in retention rate of profitable 
customers, product/service development and management performance (pre-launch activities, e.g. generating ideas, concept development, post-launch etc.) (Lawrence and Lorsch, 1967; Souder, 1977; Gupta et al. 1985; Carlsson, 1991; John and Hall, 1991; Griffin and Hauser, 1992; Griffin and Hauser, 1996; Kahn, 1996; Kahn and Mentzer, 1998: Jassawalla and Sashittal, 1998; Isaksson, 2005). The item, "IFI" concerns to the ability of a company to integrate different functional department in order to deliver higher customer value. Integration within the marketing and IT departments refers their ability to integrate exchange related activities in order to facilitate planning, implementation, and usage of CRM system. It requires cross functional planning, coordination, and sharing of information to improve OP.

Figure 1: The Proposed Conceptual Model

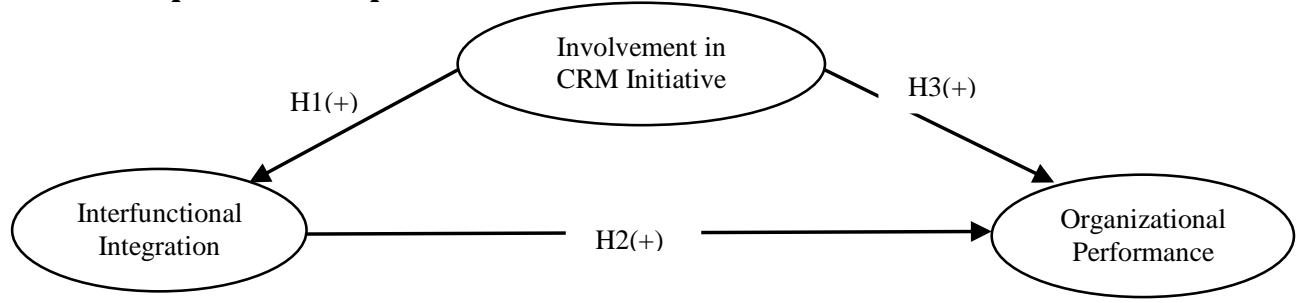

Involvement (IN) in CRM Initiative and Inter-Functional Integration (IFI): Information Technology (IT) is contributing a critical role in CRM, because it enables to manage the customer information and creation of customer knowledge that is important to retain the customers (Cooper et al., 2000). Moreover, CRM system and involvement of different functions of the company in its planning, implementation and usage play an important role in building a strategic bridge among different functions of the company in enhancing the long-run relationship with the customers. CRM initiative is complex and difficult, because its implementation touches several functions such as finance, accounts, operation, marketing, human resource, sales, IT, manufacturing, R \& D and others departments within a company (Sheth and Parvatiyar, 1995; West, 2001; Rigby et al., 2002; Sathish et al., 2002; Adebanjo, 2003). According to Galbreath (1998), the most important role of CRM is to incorporate and influences several functions especially marketing, sales, and service functions through business process automation, technology solutions, and information resources to enhance every customer contact. Although, each functional area (i.e. marketing and IT) performs particular organizational tasks, and this inter-departmentalization is the cause of much conflict and creates many implementation and usage problems that are ultimately effects organizational performance (Crittenden et al., 1993; Ryals and Knox, 2001; Isaksson, 2005; Payne, 2006).

Many studies have indicated the IFI needs to be achieved across company boundaries. Higher level of IFI requires fluent flow of accurate, clear, concise, sufficient and timely information across the organization. CRM system has the potential to provide the links and manage the information flow that support collaboration and communication over different functions of the company. One of the most important interfaces that affected by CRM implementation is between marketing and IT departments. For example, a research survey of 55 (mainly large European) companies exposed that these two (Marketing and IT) departments have been involved in CRM implementation projects (Alt and Puschmann, 2004). Therefore, cooperation and coordination between marketing and IT functions is crucial for their effective IFI. Marketing leads function in managing customer relationships (Srivastava et al., 1999; Isaksson, 2005) and IT is "glue" that enables the operationalization of CRM (Ryals and Payne, 2001; Isaksson, 2005) and this interface emerges as vital (Glazer, 1997; Ryals and Knox, 2001; Daniel et al., 2003; Isaksson, 2005). Daniel et al. (2003) also pointed out that these two functions traditionally have been placed in two separate departments, enhancement in IT which improving marketing practices have made it impossible to overlook this facet, therefore it increases interdependent between these two departments. This calls for a considerable degree of cross-functional co-operation, interaction, and coordination (Payne and Frow, 2006).

Moreover, the members of the marketing and IT departments interact either personally or via exchange of written information while CRM system initiative, they can reach mutual agreements on both how it can be developed and implement to match the marketing departments' needs and how the system can be used. Here, involvement of marketing in planning, implementation, and usage of CRM system as key enabler of IFI through the capture, organization, and sharing of important information within marketing and IT (Isaksson, 2005). Therefore, this involvement of marketing department with IT in the CRM 
initiative can boost the IFI between marketing and IT departments that ultimately affect OP. On the basis of above discussion, a following proposition can be proposed;

Proposition 1: Involvement of marketing department in CRM initiative has a positive impact immediately on Interfunctional integration (IFI).

Inter-Functional Integration (IFI) and Organizational Performance (OP): Payne and Frow (2006) adopted holistic definition of CRM defined by Bohling et al. (2005); "CRM is a strategy that manage the intelligent use of data and technology, the acquisition of customer knowledge and the diffusion of this knowledge to the appropriate stakeholders, the development of appropriate (long-term) relationships with specific customers and/or customer groups, and the integration of processes across the many areas of the firm and across the network of firms that collaborate to generate customer value" (p. 138). This view highlights the importance of IFI of processes of different functions and going beyond the functional boundaries over the entire organization in order to boost up the organizational performance. It is believed that all of the members that comprise the different functions should be managed as a single complete system that leads to the superior OP. Moreover, integration can also be defined as "a unite effort of various functions in the accomplishment of organizational goals". The literature reviews of both empirical and theoretical studies have come to the consensus that IFI can enhance OP (Gupta et al., 1985; John and Hall, 1991; Griffin et al., 1996; Knox and Ryals, 2001; Meyer, 2005; Isaksson, 2005; Kim and Lee, 2010). It also supports that inter-functional relation of marketing with IT contributes successful marketing programs and organization wide processes (Gupta et al., 1985; John and Hall, 1991; Griffin et al., 1996; Isaksson, 2005).

IFI between marketing and IT can be improved by consistent interaction and collaboration between them. There are two perspectives of interaction: i) interpersonal interaction (meetings) and ii) written interaction (Kahn and Mentzer, 1998; Isaksson, 2005). Interpersonal and written interaction are defined as" exchange processes of interpersonal and written information between different departments". For accomplishing their jobs, they have to exchange information, resources, and technical capabilities. From collaboration perspective; integration consist of collaborative behavior, mutual goals, mutual understanding, shared resources, working together, collective goals, common vision and shared values (Kahn and Mentzer, 1998; Isaksson, 2005; Meyer, 2005; Kim and Lee, 2010). Therefore, inter-functional collaborative initiative is more or less structure, informal, and more focused. Moreover, internal functions are interdependent due to distinct goals, skills, resources, and abilities (Isaksson, 2005) that ultimately require effective IFI. It is concluded that interaction and collaboration processes between marketing and IT departments can reduces conflicts and tensions that ultimately improve OP (Souder, 1977; Ryals and Knox, 2001; Isaksson, 2005; Meyer, 2005; Kim and Lee, 2010).

Performance can be measured as departmental performance, level of satisfaction of a department working with other, product development and management performance (pre-launch activities, e.g. generating ideas, concept development, post-launch etc.), customer service performance, and overall organizational performance (Kahn and Mentzer 1998; Isaksson G., 2005). Performance of marketing department can be measured as expansion of marketing campaign, time to reach customer, reduction in operational cost, building virtual community, and retention of profitable customers. These can be used as performance measureable variables to reflect the CRM environment. Payne (2006) identified a gap between marketing and IT function. These Inter-functional conflicts affect the OP. Therefore, there is a great need for effective IFI to achieve the common organizational goals and marketing department can enhance its performance by having effective communication with IT department. Thus, a following proposition can be proposed on the basis of the foregoing considerations:

Proposition 2: Inter-functional integration (IFI) of marketing with IT will positively influence organizational performance (OP).

Involvement (IN) in CRM Initiative and Organizational Performance (OP): The main aim of CRM is to enhance marketing output by identifying and attracting new customers, understanding their needs and wants, providing them customized product and excellent service, and foreseeing their needs that is achieved by improving marketing efficiency and effectiveness (Parvatiyar and Sheth, 2001; Payne, 2006). Few organizations also consider that customer information management is the sole responsibility of marketing department. After CRM implementation, marketing efficiency can be achieved by efficiently managing customer information, shrinking overall development and transaction costs for the organizations via more cooperative, collaborative and effective processes between marketing and IT 
functions. In result of effective CRM implementation, organizational profit and revenue will increase (Goodhue et al., 2002, p.80).

The effect of the CRM system initiative on OP has been long standing discussion and major concern among researchers and managers. Several studies have been conducted ranging from the investigation to streamline of specific CRM applications with the organizational strategic objectives (Isaksson, 2005; Payne, 2006) to the comparative analysis of CRM applications and method of its use. However, the studies conducted to measure the direct effect of CRM implementation on OP has depicted inconsistent results, because few organizations reported that they have received desired results and others was not able to reap the benefits of CRM implementation (Sigala, 2004; Krasnikov et al., 2009). Thus, there are external factors other than CRM applications influence its effective implementation that ultimately contributes OP.

There are several factors including user involvement which affect the success of the projects. According to Keil and Erran, (1995), successful software projects employed more user involvement as compare to failure projects that employed less user involvement. However, there is strong and direct relationship between user involvement and user satisfaction (McKeen et al., 1994) that consequently affect the OP. The way of using a system is important for determining the performance. When user try to use a system in a badly manner or avoid using it, then it is very difficult to achieve expected outcomes. Isaksson (2005) identified involvement as an independent variable for measuring the effect of involvement in CRM implementation initiative on performance which was not supported from the perspective of large Swedish companies. But, there might be evidences in companies of other countries like Pakistan that user involvement in the planning, implementation, and usage of CRM system results that company can deliver products reliably and quickly, enhance responsiveness, shorten lead time, enhance marketing campaign and improve the OP. because, it is highlighted in different studies that there is critical relationship between technology acceptance and OP (Davis, 1989, Davis et al., 1989, Denial et al., 2003). However, it is expected that user involvement in planning, implementation, and usage of CRM system would have positive influence on performance. Therefore, it can be proposed in the following proposition on the basis of foregoing discussion:

Proposition 3: Involvement (IN) of marketing staff in planning, implementation, and usage of CRM system shall has immediate positive effect on organizational performance (OP).

\section{Methodology}

Sampling and Data Collection: Primary data for this study was collected from a survey of 30 large companies in Pakistan. It was quite difficult to collect data from all parts of the given Pakistan's geographic size. The survey was carried out in mainly four large cities; Karachi, Lahore, Faisalabad, and Rawalpindi/Islamabad which have received a lot of economic reform and development, are the most representative of developed areas in Pakistan. In order to achieve higher accuracy regarding data collection from right person, large companies from different industries rather focusing on one industry were selected. The reason for selecting large companies is that they have several different functions like marketing and IT departments and also implemented or planning to implement CRM system (Agarwal et al., 2004). It was not sure regarding which company has CRM system and which has not, because companies were selected randomly according to the popularity of the company and the size of the industry. First, the higher ranking officers of the targeted companies were contacted by telephone calls (telephone numbers were taken from their companies' websites), after that the managers responsible for the company's marketing activities were contacted, to let them know about the importance, usefulness and nature of the survey. Therefore, all the respondents were marketing managers and it is rational to expect that they have deep insight into the marketing activities and the most involved in the crossfunctional activities in order to achieve collective strategic objectives and are knowledgeable regarding the content of the survey or inquiry.

Respondents were encouraged to provide reliable data according to their knowledge and experience in order to meet the validity and reliability criteria (Miller et al., 1997). It was promised about the confidentiality of their data provided and they would receive a report of the results of the study in the end. Thus, the author did best to reduce response biases in the collected data. During discussion with managers on telephone, their email addresses were asked for sending online survey. The survey questionnaire was designed on the website link provided by the Mid Sweden University, Sweden and it is easiest way to collect required data when respondents are geographically far away. During this process, 
each manager was contacted to inform about the purpose of the study before sending online survey questionnaire in order to complete sample of all 125 companies located in different four cities of Pakistan. After every two weeks, follow up emails and phone calls were done to remind regarding answering the survey questionnaire. At last, 66 responses were received and 29 respondents just accessed the web link of survey questionnaire, but they didn't complete them. The numbers of usable questionnaires were 54 out of total received 66 responses and remaining 11 responses were not usable because of significant data missing and incompleteness. Out of these responses, 30 responses were from those companies which have implemented or planning to implement CRM system and 24 responses from those companies which do not have CRM system. The author focuses only those companies which have implemented or implementing CRM system due to relevance of the data. Thus, the final usable sample consist 30 respondents yielding a usable response rate of $24 \%$.

Construct Measure: The author followed the steps recommended by Cooper et al. (2000) in scale development. Each factor was clearly defined and the literature review was done to find any relevant scales. Each measure is adopted from previous literature where it is considered to be appropriate especially a study conducted by Isaksson, 2005. The questionnaire was consisted of two sections. The first section dealing with inter-functional relations and OP, and second section regarding CRM system opened with a definition of CRM and CRM systems. All questions were close-ended and the survey was modest in length. Two types of scale such as 5 ordinals ranging from "never" to "quite frequently" and 7 likert scale ranging from extremely disagree to extremely agree, and including the additional descriptive of small extent to large extent in order to measure involvement of marketing in planning, implementation, and usage of CRM system were used in the survey questionnaire. Block of questions regarding inter-functional activities of marketing department with IT department was adopted from Kahn (1996); Kahn and Mentzer (1998), and Isaksson (2005). Questions related to performance were asked in percentage from $0 \%$ to $100 \%$, with $100 \%$ representing perfect performance. And involvement in the CRM system was measured by means of three items such as involvement in planning, implementation, and usage of CRM system. The closest alternative was to send questionnaire by mail, but it was too expensive for us.

Data Analysis Techniques: The data is processed using Microsoft Excel and Statistical Package of the Social Sciences (SPSS). Correlation and descriptive statistics are employed which include minima, maxima, mean, Skewness, kurtosis, standard deviation for investigating the relationship among IN of Marketing departments in planning, implementation and usage of CRM system, IFI and OP. Descriptive statistics measure patterns and general trends in a data set. The measures which used to describe the data set are the measures of central tendency and measures of variability or dispersion. Simple regression analysis is also used to investigate propositions illustrated above in literature review. Regression is a valid statistical technique to analyze the causal relationships between single dependent and one or more independent variables in order to measure to what extent or degree an independent variable causes variances in the dependent variable (Hair at el., 2003; Isaksson, 2005).

Multicollinearity: Collinearity or multicollinearity sometime poses problem, Variance Inflation Factors (VIFs), Eigen Value, and Tolerance are used as collinearity statistics to measure collinearity among data as depicted in table 1. If VIFs are greater than 5, multi-collinearity can unduly influence the results of regression analysis. All VIFs' values are less than 2.50, eradicate this possibility. A tolerance of less than 0.20 indicates multi-collinearity exists among data, but all tolerance values in this study are greater than 0.40 , rolling out this possibility.

Table 1: Collinearity Statistics

\begin{tabular}{llll}
\hline Constructs & Tolerance & VIF & Eigen Values \\
\hline Interpersonal Interaction & 0.60 & 1.66 & 0.03 \\
Written Interaction & 0.46 & 2.18 & 0.03 \\
Collaboration & 0.60 & 1.66 & 0.02 \\
Involvement & 1.00 & 1.00 & 0.02 \\
Organizational Performance & 1.00 & 1.00 & 0.02 \\
\hline
\end{tabular}

Validity Analysis: Validity is an important technique to measure the trust worthiness of the study. Validity refers to what extent or degree a study accurately replicate or asses the specific concept that an investigator trying to investigate. Validity can be measured in three different ways; measurement validity, internal validity, and external validity. In order to increase measurement validity, the author reviewed 
the previous research literature regarding the conceptualization of factors and found most of the measurements of this study in previous researches. Two factors interactions and collaboration of interfunctional integration has been adopted from previous work done by Kahn and Mentzer (1998), and Isaksson (2005). Moreover, this study has been discussed and evaluated with managers at different companies. External validity concerns with the generalizability of the results of the study. Generalization of the findings of this study to other setting, especially regarding company size, culture, and country must be considered an issue. This study is contacted on large Pakistani companies and it may limit the generalizability of the study, because CRM implementation and inter-functional relationships are associated with culture.

Reliability Analysis: Black (1999) pointed out that the reliability concept has three perspectives: consistency over time, internal consistency, and consistency between observers. Internal consistency refers the uniformity of the respondents on different items of the same construct and estimated by Cronbach's alpha test (Hull and Nie, 1981). Cronbach's alpha values ranges from zero (no internal reliability) to 1 (perfect internal reliability), and a minimum acceptable and critical alpha value of 0.7 is considered (Hair et al., 2003). As shown in table 2, all alpha values of the factors are higher than critical alpha value of 0.7 and it suggests that these theoretical factors have good internal reliability.

Table 2: Measurement of Internal Reliability

\begin{tabular}{lll}
\hline Factors & No. of items & Cronbach's alpha value \\
\hline Interpersonal Interaction & 4 & 0.72 \\
Written Interaction & 5 & 0.74 \\
Collaboration & 6 & 0.94 \\
Involvement & 3 & 0.97 \\
Organizational Performance & 12 & 0.79 \\
\hline
\end{tabular}

\section{Findings}

Correlation and Descriptive Statistics: Statistical tool Pearson correlation is applied for findings the degree of relationship among IN, IFI, and OP. Generally, two variables tend to move or vary in the same or opposite direction. If both variables tend to vary - increase or decrease - together, the correlation between them is considered positive or direct. If both variable tend to vary - increase or decrease - in different direction or if one variable increases and other variable decreases, then it is said to be inverse or negative correlation. Statistically, correlation value ranges from -1 means perfect negative correlation, 0 means no correlation, to +1 means perfect positive correlation. Correlation among IN, IFI, and OP is shown in table 3 and descriptive statistics consisting mean, standard deviation, range, maximum, minimum, sum, Skewness, kurtosis, and count are exposed in table 4.

Table 3: Correlation of Variables

\begin{tabular}{llll}
\hline Variables & IN & IFI & OP \\
\hline Involvement (IN) & 1 & & \\
Inter-functional Integration (IFI) & 0.973 & 1 & \\
Organizational Performance (OP) & 0.423 & 0.500 & 1 \\
\hline
\end{tabular}

Table 4: Descriptive Statistics

\begin{tabular}{llll}
\hline & IN & IFI & OP \\
\hline Mean & 3.91 & 3.88 & 62.14 \\
Standard Deviation & 0.81 & 0.85 & 17.83 \\
Range & 4 & 4 & 78.8 \\
Maximum & 5.2 & 5.3 & 94.6 \\
Minimum & 1.2 & 1.3 & 15.8 \\
Sum & 117.4 & 116.5 & 1864.3 \\
Skewness & -1.271 & -1.005 & -0.610 \\
Kurtosis & 2.949 & 1.630 & 0.254 \\
Count & 30 & 30 & 30 \\
\hline
\end{tabular}


There is positive correlation of 0.973 between IN and IFI; the mean of IN is 3.91 and standard deviation of IN is 0.81 indicating that the most of the marketing managers are agreed with the positive and greater effect of their involvement in CRM initiative on inter-functional integration in different companies of Pakistan. This high correlation that is near to perfect positive correlation support that whenever there is rigorous and effective IFI, there is marketing and IT managers both participate in the planning, implementation and usage of CRM system. In other words, whenever different department members are involved in that kind of project leads to effective IFI among them. Even though, low participation of managers in CRM initiative contributes strong and effective IFI. There is also positive correlation of 0.50 between IFI and OP; the mean and standard deviation of IFI are 3.88 and 0.85 respectively also indicates that marketing managers have different opinion due to higher standard deviation about the association between IFI and OP, but still over all there is good positive correlation between them. Whenever, marketing managers communicate via interpersonally- attend meeting together, phone conversation, or exchange of written information with IT department and have collaboration that leads effective IFI between them ultimately OP goes up or moves in the positive direction. Correlation between IN and OP is 0.423 reflect that there is positive association between them. When company allows employees to participate or involved in planning for target project development and implementation of CRM system results its effective and successful implementation that ultimately increases the OP. Thus, IN of other departments in CRM initiative with IT department is important and senior management should give attention, because it has positive association or correlation with OP directly as well as indirectly mediated by IFI.

Regression: Simple linear regression model is also used in order to find the contribution of independent variable toward dependent variable. Three propositions regarding conceptual model are proposed. Proposition 1 claimed that Involvement (IN) of marketing department in CRM initiative has a positive impact immediately on Inter-functional integration (IFI). Table 5 shows regression values regarding first proposition. In this model, $94.7 \%$ variability in inter-functional integration (IFI) is explained by involvement (IN) of marketing in the planning, implementation and usage of CRM system with coefficient value of $0.973(t=22.38, p<000)$, indicating that increasing one unit of IN will increase IFI by 0.973 . Hence, proposition 1 is empirically accepted which is that there is high and significant positive relationship between involvement in CRM initiative and IFI.

Table 5: Effect of IN CRM initiative on IFI

\begin{tabular}{lccl}
\hline Independent Variable & B & T & Sig. \\
\hline Involvement (IN) & 0.973 & 22.380 & 0.000 \\
\hline Note: R-square $=0.947, \mathrm{~F}=500.854(\mathrm{p}<0.00)$ &
\end{tabular}

Proposition 2 claimed that Inter-functional integration (IFI) of marketing with IT will positively influence organizational performance (OP). As shown in table 6, in this model, this proposition 2 is supported empirically $(B=0.50, t=3.055, p<0.005)$. Moreover, IFI explained $25 \%$ variability in dependent variable of OP. This means that IFI has significant positive influence on OP. IFI has strong relationship with OP is consistent with the results from previous studies as well (Kahn, 1996; Kahn and Mentzer, 1998; Isaksson., 2005). It is evident that integration focuses on interpersonal interaction, written interaction, and collaboration has positive effect on performance. But a certain level of written interaction and collaboration is always required for achieving desired performance; otherwise too much interaction and collaboration diminished performance (Narver and Slater, 1990; Maltz and Kohli, 1996; and Isaksson, 2005).

Table 6: Effect of IFI on OP

\begin{tabular}{llll}
\hline Independent Variable & B & T & Sig. \\
\hline $\begin{array}{l}\text { Inter-functional Integration } \\
\text { (IFI) }\end{array}$ & 0.50 & 3.055 & 0.005 \\
\hline
\end{tabular}

Note: $\mathrm{R}$-square $=0.250, \mathrm{~F}=9.330(\mathrm{p}<0.00)$

Proposition 3 predicted that Involvement of marketing staff in planning, implementation, and usage of CRM system will positively affect directly OP. Results of the investigation of this hypothesis are illustrated in table 7. This relationship is supported $(\mathrm{B}=0.423, \mathrm{t}=2.467, \mathrm{p}<0.020)$. Moreover, involvement of managers explained $17.9 \%$ variance in dependent variable OP. It means that involvement effect the performance. But it show little variability (18\%) and not perfect significance $(0.020)$, because several organizations had 
high user satisfaction and better performance despite little participation in the planning and implementation of CRM system. It was also expected that involvement of marketing managers in the planning, implementation, and usage of CRM system contribute to better performance (McKeen et al., 1994).

Table 7: OP by IN in CRM initiative

\begin{tabular}{llll}
\hline Independent Variable & $\mathbf{B}$ & T & Sig. \\
\hline Involvement $(\mathrm{IN})$ & 0.423 & 2.467 & 0.020 \\
\hline Note: R-square $=0.179, \mathrm{~F}=6.086(\mathrm{p}<0.005)$ & &
\end{tabular}

In this research, it is explored that the involvement of marketing managers with IT department in the planning, implementation, and usage of CRM system not only improve the inter-functional integration, but also boost up the performance directly. Moreover, mediation effect of IFI upon the relationship of IN with OP is also supported. So, involvement of different departments in CRM initiative is considered important for IFI and OP rather than avoiding the participation of other functions, because joint decision or planning can reaches the agreement about how the system should be, and how it is implemented and used which causes effective CRM implementation. Further, the most benefited by this system is marketing department (Galbreath, 1998; Srivastava et al., 1999; Parvaitivar and Sheth, 2001; Isaksson, 2005) along with other departments.

\section{Discussion and Implication}

Discussion: The objective of the study is to propose a conceptual model of relationship among IN, IFI, and OP that results theoretical and practical implications. 1st, an important contribution of this research is the empirical investigation of the relationship in the literature on the effect of IN on IFI and OP. As concerned to the author's knowledge, it is the first empirical study that measures the causal relationship among three factors: IN, IFI, and OP, even though there are few other studies closer to this study like an empirical study conducted to investigate the relationship of IFI with OP (Isaksson, 2005) and theoretical study conducted to examine the organizational issues relating to culture \& communication and inter-functional integration between marketing and IT (Ryals and Knox, 2001). Moreover, many organizations are trying to explore new ways to increase OP as well as IFI by investing in CRM system, but still there exist "IT paradox" and no clear whether CRM implementation enhance IFI and OP. therefore, this research proposes a conceptual model where IN and IFI bridges CRM implementation and OP. The model discloses the effect of involvement of different functions in the planning, implementation, and usage of CRM system on IFI and OP along with IFI has positive influence on OP, which results effective CRM implementation.

2nd, this research seeks to give the answers of two questions: 1) Does involvement in CRM initiative immediate impact on IFI and OP? As hypothesized in first and third propositions; IN has immediate effect on both IFI and OP. The study finds that there is strong and significant positive effect on IFI. There is also positive effect of IN on OP due to effective CRM implementation, but not perfect significant. 2) How does the involvement in CRM initiative affect OP? As proposed in first and second propositions; mediation effect of IFI causes positive relationship between IN and OP. Involvement in CRM initiative results desired effective CRM implementation that effects the OP via strong IFI. In other words, IN results positive and significant effects on IFI directly and then IFI reveals positive relationship with OP. Infect IFI is the output of human interaction and collaboration that cannot be replaced by CRM application. Here is an important point to note for the managers whenever they plan or consider investing money and time in any CRM system implementation. On the basis of the results of this study, they should give priority to the participation of different stakeholders (departments) in CRM initiative that enhances inter-functional integration (IFI) and OP. Thus, investment in CRM implementation should improve the IFI within the organization as a competitive advantage. This study conducted to integrate the critical factors for successful CRM implementation that affects the organizational performance via effective internal integration.

Managerial Implication: The research findings provide strategic framework for developing practical strategies for CRM initiative and effective IFI in order to boost up the OP. An important finding of this study is that IFI is influenced by involvement in CRM initiative and moreover, IFI is a mediate the causal relationship between involvement in CRM initiative and OP. The research findings have important and effective implications for managers. 1st, IN and CRM initiative efforts that enhance IFI should be given 
high priority. Participation of managers in the different phases of CRM initiative: planning, implementation, and its usage; and CRM implementation should results in effective and efficient IFI. 2nd, involvement in CRM initiative also has direct and positive effect (even though not perfect significant) on OP that suggest senior managers to give vital consideration to IN for effective CRM implementation in order to reap desired organizational results.

3rd, the result supports that CRM application is not a real foundation of competitive advantage but it is a source of strategic competitive necessity. CRM focuses to optimize the long term customer value and satisfaction by managing the interactive relationship with the profitable customers via cooperation and knowledge sharing among internal functions of the organization. Efficient and effective communication within the organization as well as with the upstream business entities is a necessity that can causes competitive advantage. Now a day, many companies are investing a lot of money and time in implementing IT based CRM system in order to enhance better communication and minimize cost and response time to reach for managing market fluctuation. Thus, IT based system is now a necessity rather than option ( $\mathrm{Li}$ et al, 2009). If organizations want to improve IFI, they should consider investing in CRM system along with motivate the key stakeholders to participate in its planning, implementation, and usage; moreover, should not seek at once significant immediate effect on OP. Therefore, CRM initiative and involvement will contribute to improve IFI that ultimately increase the OP.

\section{Conclusion}

This study comprised three interesting and established avenues; 1) CRM and Involvement (IN) in its Initiative, 2) Inter-functional Integration (IFI), and 3) Organizational Performance (OP) that proposes a conceptual model of their relationship in order to enhance the understanding of CRM implementation.

CRM implementation is a complex process that touches several internal departments of the organization. These departments have separate functional objectives and goals causes rivalry among them that ultimately affect OP. In addition to this, more and more companies are considering implementing CRM system in order to boost up OP. Those companies focus on immediate significant effect on OP only, they usually not able to receive the desire benefits from CRM implementation that is called CRM failure. Therefore, it is necessary to understand how CRM implementation can affect OP. Involvement in CRM initiative causes its effective implementation and enabler of integration that consequently boost the OP. CRM system facilitate reliable, concise, sufficient, accurate and timely information sharing among internal departments prospect that it will enhance IFI and OP. The findings reflect that CRM implementation contribute to the performance through its significant and potential positive effect on IFI, even though there is also positive, but not significant direct impact on OP. This study highlights the significance for management to endorse IFI and involvement in CRM initiative as enabler.

Limitations and Future Research Avenues: As other studies, numerous limitations as well as further research avenues are needed to be noted in this study. While conducting research survey and writing report, interesting issues and topics are came a across those can be considered for future research.1st, in conceptual model of relationship, there are several other factors that affect the IFI and OP remained unanswered and needs further investigation. Future study should explore and consider such other factors to assist management in order to find effective ways to improve IFI and OP. 2nd, generalization of the findings of this study to other settings, especially regarding company size, culture, and country must be considered an issue. Because, the data is collected from organizations located different four developed cities in Pakistan and moreover, these organizations belong to different industries. Organizations from other area or underdeveloped part of the country or one particular industry or others countries in the world may have different research findings due to different culture, different business principles and conditions, different management styles, and so on; might have influence on IFI and OP. Thus, further studies are needed in order to verify that the findings of this study reported here are correspond to other areas as well as conditions.

3th, there are also numerous limitations in the perspective of survey conducted. In this study, data is gathered from single informant (i.e. marketing manager) from each of 30 companies. The research findings are based on the responses of marketing mangers only, but data collected from both marketing and IT manager can provide more effective results and explanations that could improve the validity of the research findings. Therefore, future study may be conducted to investigate the relationship among IN, IFI, and OP using cross-sectional data. Finally, this study based on the proposed conceptual model of 
relationship is still in its infancy. A number of researches can be undertaken in this avenue in future. Therefore, it is encouraged that researchers and managers to show their expertise by taking up these challenges.

\section{Reference}

Abbott, J., Stone, M. \& Buttle, F. (2001). Customer Relationship Management in Practice - A Qualitative Study. The Journal of Database Marketing, 9(1), 24- 34

Adebanjo, D. (2003). Classifying and Selecting e-CRM Applications: An Analysis- Based Proposal. Management Decision, 41(6), 570-577.

Agarwal, A., Harding, D. P. \& Schumacher, J. R. (2004). Organizing for CRM. McKinsey Quarterly, 3, 80-91.

Alt, R. \& Puschmann, T. (2004). Successful Practices in Customer Relationship Management. Paper presented at the Proceedings of the 37th Hawaii International Conference on System Sciences.

Black, T. R. (1999). Doing Quantitative Research in the Social Sciences: An Integrated Approach to Research Design, Measurement and Statistics. London: Sage.

Bohling, T., Bowman, D., LaValle, S., Mittal, V., Narayandas, D., Ramani, G. \& Varadarajan, R. (2006). CRM Implementation Effectiveness Issues and Insights. Journal of Service Research, 9(2), 184-194

Carlsson, M. (1991). Aspects of the Integration of Technical Functions for Efficient Product Development. R \& D Management, 21(1), 55-66.

Cooper, B. L., Watson, H. J., Wixom, B. H. \& Goodhue, D. L. (2000). Data Warehousing Supports Corporate Strategy at First American Corporation. MIS Quarterly, 24(4), 547-567.

Crittenden, V. L., Gardiner, L. R. \& Stam, A. (1993). Reducing Conflict between Marketing and Manufacturing. Industrial Marketing Management, 22(4), 299-309.

Daniel, E., Wilson, H. \& McDonald, M. (2003). Towards a Map of Marketing Information Systems: An Inductive Study. European Journal of Marketing, 37(5), 821-847.

Davis, F. D. (1989). Perceived Usefulness, Perceived Ease of Use, and User Acceptance of Information Technology. MIS Quarterly, 13(3), 318-340.

Davis, F. D., Bagozzi, R. P. \& Warshaw, P. R. (1989). User Acceptance of Computer Technology: A Comparison of Two Theoretical Models. Management Science, 35(8), 982-1003.

Dehning, B. \& Richardson, V.J., (2002). Returns on Investments in Information Technology: A Research Synthesis, Journal of Information Systems, 16 (1), 7-30.

Galbreath, J. (1998). Relationship Management Environments. Credit World, 87(2), 14-22.

Grandhi, S. \& Chugh, R. (2012). Strategic Value of mobile CRM Applications: A Review of Mobile CRM at Dow Corning and DirecTV. International Conference on Innovation and Information Management, 36(2), IPCIT press, Singapore.

Goodhue, D. L., Wixom, B. H. \& Watson, W., J. (2002). Realizing Business Benefits through CRM: Hitting the Right Target in the Right Way. MIS Quarterly executive, 1(2), 79-94.

Glazer, R. (1997). Strategy and Structure in Information-Intensive Markets: The Relationship between Marketing and IT. Journal of Market Focused Management, 2(1).

Griffin, A. \& Hauser, J. R. (1996). Integrating R\&D and Marketing: A Review and Analysis of the Literature. Journal of Product Innovation Management, 13(3), 191-215.

Griffin, A. \& Hauser, J. R. (1992). Patterns of Communication among Marketing, Engineering and Manufacturing: A Comparison between Two new Product Teams. Management Science, 38(3), 360-373

Gupta, A. K., Raj, S. P. \& Wilemon, D. L. (1985). R and D and Marketing Dialogue in High-Tech Firms. Industrial Marketing Management, 14(4), 289-300.

Hair, J. F., Babin, B., Money, A. \& Samouel, P. (2003). Essentials of Business Research Methods (International Ed.). New Jersey: John Wiley and Sons, Inc.

Hull, C. H. \& Nie, N. H. (1981). SPSS Update 7-9: New Procedures and Facilities for Releases 7-9.

Isaksson, G. (2005). Managing the Implementation of Customer Relationship Management from an Interfunctional Perspective. Luleå University of Technology, Sweden. ISSN: 1402 -1757

Kahn, K. B. (1996). Interdepartmental Integration: A Definition with Implications for Product Development Performance. Journal of Product Innovation Management, 13(2), 137-151.

Kahn, K. B. \& Mentzer, J. T. (1998). Marketing's Integration with other Departments. Journal of Business Research, 42(1), 53-62.

Keil, M. \& Erran, C. (1995). Customer-Developer Links in Software Development. Communications of the $A C M, 38(5), 33-50$. 
Kim, C. \& Lee, M., (2010). The Effects of Collaboration between Marketing and Production on Internal and External Performance. California Journal of Operations Management, 8, 11-20.

Kohli, R. \& Devaraj, S. (2003). Measuring Information Technology Payoff: A Meta-Analysis of Structural Variables in Firm-Level Empirical Research. Information Systems Research, 14(2), 127-145.

Krasnikov, A., Jayachandran, S. \& Kumar, V. (2009). The Impact of Customer Relationship Management Implementation on Cost and Profit Efficiencies: Evidence from the U.S. Commercial Banking Industry. Journal of Marketing, 73(6), 61-77.

Jassawalla, A. R. \& Sashittal, H. C. (1998). An Examination of Collaboration in High-Technology New Product Development Processes. Journal of Product Innovation Management, 15(3), 237-254.

Li, G., Yang, H., Sun, L. \& Sohal, A. S. (2009). The impact of IT implementation on Supply chain integration and performance. Int. Journal of Production Economics, 120, 125-138

Maltz, E. \& Kohli, A. K. (1996). Market Intelligence Dissemination across Functional Boundaries. Journal of Marketing Research, 33(1), 47-61.

McKeen, J. D., Guimares, T. \& Wetherbe, J. C. (1994). The Relationship between User Participation and User Satisfaction: An Investigation of Four Contingency Factors. MIS Quarterly, 18(4), 427-452.

Meyer, M., (2005). Multidisciplinarity of CRM Integration and its Implications. 38th Hawaii International Conference on System Sciences.

Miller, W. J., McDonald, J. F. \& Pinsker, W. (1997). Molecular domestication of mobile elements. Genetica, 100(1-3), 261-270.

Narver, J. C. \& Slater, S. F. (1990). The Effect of a Market Orientation on Business Profitability. Journal of Marketing, 54(4), 20-30.

Nguyen, T. H., Sherif, J. S. \& Newby, M. (2007). Strategies for successful CRM Implementation. Information Management \& Computer Security, 15(2), 102-115.

Payne, A. (2002). The value creation process in customer relationship management. Insight Interactive, 117.

Payne, A. (2006). Handbook of CRM: achieving excellence in customer management. Routledge.

Payne, A. \& Frow, P. (2006). Customer Relationship Management: From Strategies to Implementation. Journal of Marketing Management, 22, 135-168.

Parvatiyar, A. \& Sheth, J. N. (2001). Customer Relationship Management: Emerging Practice, Process, and Discipline. Journal of Economic and Social Research, 3(2), 1-34.

Rigby, D. K., Reichheld, F. F. \& Schefter, P. (2002). Avoid the Four Perils of CRM. Harvard Business Review, $80(2), 101$.

Ryals, L. \& Knox, S. (2001). Cross-Functional Issues in the Implementation of Relationship Marketing through Customer Relationship Management. European Management Journal, 19(5), 534-542.

Sathish, S., Pan, S. L. \& Raman, K. S. (2002). Customer Relationship Management (CRM) Network: A New Approach to Studying CRM. Paper presented at the Eight American Conference on Information Systems.

Sigala, M. (2004). Customer relationship management (CRM) evaluation: diffusing CRM benefits into business processes. ECIS 2004 Proceedings, 172.

Sheth, J. N. \& Parvatiyar, A. (1995). The Evolution of Relationship Marketing. International Business Review, 4(4), 397-418.

Souder, W. E. (1977). Effectiveness of Nominal and Interacting Group Decision Processes for Integrating R\&D and Marketing. Management Science, 21(6), 669-681.

Srivastava, R. K., Shervani, T. A. \& Fahey, L. (1999). Marketing, Business Processes, and Shareholder Value: An Organizationally Embedded View of Marketing Activities and the Discipline of Marketing. Journal of Marketing, 63(4), 168-180.

St. John, C. H. \& Hall, E. H. J. (1991). the Interdependency between Marketing and Manufacturing. 20(3), 223-229.

Wahlberg, O., Strandberg, C. \& Sandberg, K. W. (2009). Trends, Topics and Under-Researched Areas in CRM Research-A Literature Review. International Journal of Public Information Systems, 5(3).

West, J. (2001). Customer Relationship Management and You. IIE Solutions, 33(4), 34-37. 